\title{
Protection of Citrus Rootstocks Against Phytophthora spp. with a Hypovirulent Isolate of Phytophthora nicotianae
}

\author{
G. C. Colburn and J. H. Graham
}

University of Florida, Citrus Research and Education Center, Department of Soil and Water Science, 700 Experiment Station Road, Lake Alfred 33850.

Accepted for publication 7 March 2007.

\section{ABSTRACT}

Colburn, G. C., and Graham, J. H. 2007. Protection of citrus rootstocks against Phytophthora spp. with a hypovirulent isolate of Phytophthora nicotianae. Phytopathology 97:958-963.

Phytophthora root rot of citrus in Florida is caused by Phytophthora nicotianae and $P$. palmivora. A naturally occurring isolate of $P$. nicotianae (Pn117) was characterized as hypovirulent on citrus roots. Pn117 infected and colonized fibrous roots, but caused significantly less disease than the virulent isolates $P$. nicotianae Pn198 and $P$. palmivora Pp99. Coincident inoculation of rootstock seedlings of Cleopatra mandarin (Citrus reticulata) or Swingle citrumelo (C. paradisi $\times$ Poncirus trifoliata) with the hypovirulent Pn117 and the virulent isolates Pn198 and Pp99 did not reduce the severity of disease caused by the virulent Phytophthora spp.
When either rootstock was inoculated with the hypovirulent Pn117 for 3 days prior to inoculation with virulent isolates, preinoculated seedlings had significantly less disease and greater root weight compared with seedlings inoculated with the virulent isolates alone. Recovery of the different colony types of Phytophthora spp. from roots of sweet orange (C. sinensis) or Swingle citrumelo was evaluated on semiselective medium after sequential inoculations with the hypovirulent Pn117 and virulent Pp99. Pn117 was isolated from roots at the same level as the Pp99 at 3 days post inoculation. Preinoculation of Pn117 for 3 days followed by inoculation with Pp99 resulted in greater recovery of the hypovirulent isolate and lower recovery of the virulent compared with coincident inoculation.
Phytophthora foot and root rot are the most important soilborne diseases of citrus causing mortality of newly planted trees and a slow decline and yield loss of mature trees (10). Phytophthora spp. found in Florida citrus orchards are Phytophthora nicotianae Breda de Haan (syn. P. parasitica Dastur) and P. palmivora (E. J. Butler) E. J. Butler (10). P. nicotianae is the most prevalent Phytophthora spp. in Florida citrus orchards and nurseries, whereas $P$. palmivora, causing brown rot and root rot, is restricted in occurrence $(10,11)$. In a greenhouse study of competition between isolates of the two Phytophthora spp., P. palmivora was shown to be a more aggressive pathogen because soil populations of $P$. nicotianae were always depressed in mixed inoculations (25).

Management of Phytophthora diseases includes the use of tolerant rootstocks and fungicides, but biological controls are not commercially available. Applications of the systemic fungicides metalaxyl and fosetyl-Al have been shown to increase fibrous root weight of citrus rootstocks and to reduce propagules of $P$. nicotianae (18). Although fungicides increase yields and fruit size of orange and grapefruit trees on susceptible rootstocks, yield response is often variable (9). Thus, fungicides may not always be economically justifiable $(9,10)$. Therefore, applications are not recommended unless populations of $P$. nicotianae exceed a threshold of 10 to 15 propagules $/ \mathrm{cm}^{3}$ of soil $(10,18,22)$. Fungicides usually are applied to the soil through the irrigation system two to three times over multiple seasons to be effective (10). Soilapplied fungicides are prone to loss of efficacy after prolonged usage and, because they are water soluble, have the potential to leach into the groundwater after excessive irrigation or rainfall (13). The recovery of metalaxyl-resistant isolates of $P$. nicotianae from Florida citrus nurseries raises concerns about the long-term

Corresponding author: J. H. Graham; E-mail address: jhg@crec.ifas.ufl.edu

doi:10.1094/PHYTO-97-8-0958

(C) 2007 The American Phytopathological Society usage of metalaxyl in citrus groves (21). When introduced with nursery trees, metalaxyl-resistant populations persist in Florida citrus groves (21).

Several potential biological agents have been investigated for the control of Phytophthora root rot of citrus. The ability of introduced antagonists to establish and colonize the rhizosphere soil is an important factor in successful biological control $(8,15)$. Penicillium funiculosum and Pythium nunn reduced root rot in greenhouse conditions, but the antagonism was effective only at the highest inoculum density in the soil $(5,6)$. Both biocontrol agents required an additional substrate mixed into the soil to maintain their populations and to provide control of root rot. Field studies involving control of Phytophthora root rot of citrus confirm the limitations of introduced biocontrol agents $(17,20)$. Weekly applications of Pseudomonas putida through the irrigation system were necessary to sustain the antagonist in the rhizosphere (20). Populations were not maintained in the rhizosphere if $P$. putida was applied only once a year. Efficacy of biocontrol with $P$. putida was questionable, because even frequent applications did not consistently reduce the population of Phytophthora nicotianae.

In 1996, 2-year-old Sunburst tangerine trees on Cleopatra mandarin rootstock were preinoculated with isolate Pn117 of $P$. nicotianae 6 weeks prior to transplanting the trees into a central Florida citrus orchard with endemic Phytophthora spp. (J. H. Graham, unpublished data). Isolate Pn117 is a naturally occurring isolate of $P$. nicotianae that previously was shown to be virulent (7). Preinoculated trees that did not receive fungicides were expected to have the greatest root rot. Trees inoculated with Pn117 had less disease than the noninoculated trees, an indication that the isolate controlled disease caused by virulent endemic Phytophthora spp. for several months. Pn117 isolate is considered hypovirulent because damage to roots was attenuated compared with that caused by Phytophthora spp. in the orchard. The efficacy of this hypovirulent isolate for biological control was indicated by 
lack of need for additional applications to sustain rhizosphere activity for 7 months after the trees were planted.

The potential for preinoculation with $P$. nicotianae to protect fibrous roots was first demonstrated for avocado against highly virulent $P$. cinnamomi (1). Co-inoculation with the two Phytophthora spp. did not reduce lesion development; however, inoculation with $P$. nicotianae at 2 or $24 \mathrm{~h}$ prior to inoculation with $P$. cinnamomi reduced lesion size on roots. Avocado seedlings grown in soil infested with $P$. nicotianae were stunted compared with the control plants, indicating that $P$. nicotianae is a weak pathogen of avocado roots.

In the present study, the main objective was to evaluate whether prior inoculation with the hypovirulent isolate Pn117 of $P$. nicotianae could protect roots against virulent isolates of $P$. nicotianae and $P$. palmivora. Susceptible (Cleopatra mandarin) and tolerant (Swingle citrumelo) rootstocks were chosen for evaluation (7) to determine whether rootstock affects the expression of biological control. Competition between Pn117 and the virulent isolates also was evaluated to determine the colonization and reproduction potential of Pn117 and its ability to reduce root colonization by the virulent isolates.

\section{MATERIALS AND METHODS}

Plant material and inoculation with Phytophthora spp. Seed of Ridge Pineapple sweet orange (Citrus sinensis (L.) Osbeck), Cleopatra mandarin (C. reticulata Blanco), and Swingle citrumelo (C. paradisi Macfad. $\times$ Poncirus trifoliata) were obtained from the Florida Department of Agriculture and Consumer Services, Division of Plant Industry. The seed were sown in $150-\mathrm{cm}^{3}$ containers (Stuewe \& Sons Inc., Corvallis, OR) containing Metro Mix 500 (Scotts Co., Marysville, OH). After germination, the seedlings were fertilized weekly with Peter's 20-10-20 Peat Lite Special (Scotts Co.). Six-month-old seedlings were transplanted

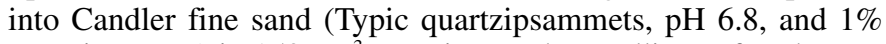
organic matter) in $150-\mathrm{cm}^{3}$ containers. The seedlings of each rootstock were selected for uniformity in size after the potting mix was removed and the roots were washed.

Phytophthora nicotianae isolate Pn117 was isolated from citrus roots in Ona, FL, P. nicotianae isolate Pn198 from citrus roots in Lake Alfred, FL, and P. palmivora Pp99 from citrus roots in LaBelle, FL. Isolates were maintained on clarified V8 juice agar by serial transfer. Chlamydospores of each isolate were produced in V8 juice broth by the method of Tsao (23) for use as inoculum. The mycelium and chlamydospores were mixed in a blender for $30 \mathrm{~s}$ and added to 10 liters of autoclaved Candler fine sand that had been moistened to field capacity. The soil was mixed manually to produce an inoculum concentrate. The concentrate was incubated at room temperature for 2 days to allow the hyphae to die so the inoculum would consist mostly of chlamydospores. To determine the propagule concentration, $1-\mathrm{cm}^{3}$ samples of the inoculum concentrate were plated on a selective medium containing pimaricin-ampicillin-rifampcin-pentachloronitrobenzenehymexazol (PARPH) $(7,16,22)$. The inoculum concentrate of each isolate was added to autoclaved Candler fine sand to provide a density of $\approx 20$ propagules $/ \mathrm{cm}^{3}$ of soil.

Phytophthora spp. interaction. Seedlings were transplanted into autoclaved Candler fine sand soil containing either isolate Pn117, Pn198 of P. nicotianae, Pp99 of P. palmivora, both Pn117 and Pn198, or both Pn117 and Pp99. Inoculum concentration initially was $\approx 20$ propagules $/ \mathrm{cm}^{3}$ per isolate. Noninoculated control trees were planted into autoclaved sand soil. Additional treatments were designed to allow the hypovirulent isolate to colonize the roots before inoculation with the virulent isolates. In this case, seedlings were transplanted into soil containing Pn117 for 3 days. Then the trees were transplanted into autoclaved soil containing either Pn198 or Pp99. Soil adhering to the roots was not removed during the transplant process. To determine that colonization by
Pn117 was the only cause for biological control, another set of seedlings was planted into autoclaved soil for 3 days. Then, the trees were transplanted into soil infested with either Pn198 or Pp99. For all treatments, 10 single seedling replications were used for each of the two rootstocks. Each replicate seedling was placed in a completely random design in the greenhouse and was moved weekly to avoid location effects. Each container was watered to runoff twice a day and was fertilized once a week with Peters 20-20-20 liquid fertilizer. Greenhouse conditions ranged from 25 to $35^{\circ} \mathrm{C}$ and 60 to $100 \%$ relative humidity. The experiment was conducted twice during June to August 2004 to provide optimal conditions for root growth, infection, and sporulation by Phytophthora spp.

Seedlings were evaluated 4 weeks after the final inoculation step. Seedlings were carefully removed from the soil to avoid breakage of roots, and roots were washed free of the adhering soil. Root tips were examined and the percentage of diseased tips on each root system was estimated by a visual rating scale from 1 to 5 , where $1=$ no visible rot and $5=$ no visible healthy roots. The root system then was dried at $70^{\circ} \mathrm{C}$ for $48 \mathrm{~h}$ and the fibrous roots of each seedling weighed. To determine the propagule density, soil from each container of the same treatment was collected, mixed, and assayed on PARPH semiselective medium.

Data from the visual disease assessment were analyzed nonparametrically (19) using Proc Mixed of SAS (version 9.1; SAS Institute, Cary, NC). Data for the two rootstocks were pooled for the analysis after it was determined that there was no significant interaction of rootstock with treatment. The data from the root weight and propagule measurements were analyzed with two-way analysis of variance (ANOVA). The analysis was performed with SAS PROC TUKEY.

Competition between isolates of Phytophthora spp. Threemonth-old sweet orange or Swingle citrumelo seedlings grown in $150-\mathrm{cm}^{3}$ containers were inoculated with chlamydospores. There were four inoculation treatments: (i) Pp99, (ii) Pn117, (iii) coinoculation with Pp99 and Pn117, and (iv) preinoculated with Pn117 3 days before transplanting into soil containing Pp99. For all treatments, 10 single seedling replications were used per rootstock. Inoculum concentration was $\approx 20$ propagules $/ \mathrm{cm}^{3}$ per isolate. Each container was watered to runoff twice a day. Greenhouse conditions ranged from 25 to $35^{\circ} \mathrm{C}$ and 60 to $100 \%$ relative humidity. At 3 days after transplanting, seedlings were carefully lifted from the pot and root systems were washed free from the soil, keeping the roots intact. The entire root system was cut into segments and placed onto PARPH medium based on nutrient agar (NA) base instead of the corn meal agar (CMA) used in previous competition experiments (25). P. palmivora forms small, dense colonies and $P$. nicotianae larger, spreading colonies on PARPH with either CMA or NA as the base; however, colony morphology differences are greater when the colonies are growing on NA (25). The experiment was conducted twice within the same summertime period. The data from the treatments were analyzed with one-way ANOVA for each rootstock separately.

\section{RESULTS}

Phytophthora spp. interaction. For both Cleopatra mandarin and Swingle citrumelo seedlings, roots inoculated with Pn117 had significantly lower disease severity $(P<0.0001)$ and greater root weight than trees inoculated with either Pn198 or Pp99 (Tables 1 and 2). Seedlings inoculated with the Pn117 isolate for 3 days before exposure to $\mathrm{Pn} 198$ or Pp99 had lower disease severity than seedlings inoculated with Pn198 or Pp99 alone (Table 1). Coincident inoculation of the roots with Pn117 and either Pn198 or Pp99 did not reduce disease severity compared with the virulent isolates alone. Seedlings that were planted in autoclaved soil 3 days before inoculation with Pn198 or Pp99 did not have less disease than seedlings inoculated at the start of the experiment. 
Disease severity was not significantly different between the two citrus rootstocks $(P=0.321)$. The interaction of rootstock and isolate treatment was not significant $(P=0.815)$; therefore, the disease severity data for the two rootstocks and the repetition of the experiment were pooled for further analysis. For the pooled data, disease severity was significantly lower in seedlings treated with Pn117 than seedlings treated with Pn198 or Pp99 (Fig. 1). Disease severity also was significantly lower in seedlings treated with Pn117 for 3 days before inoculation with a virulent isolate than seedlings treated with Pn198 or Pp99 alone.

For each rootstock, root weight was significantly greater for seedlings that had received a 3-day exposure to Pn117 before inoculation with either virulent isolate than seedlings inoculated with a virulent isolate alone (Table 2). Seedlings co-inoculated with Pn117 and either virulent isolate did not significantly differ in root weight from seedlings inoculated with each virulent isolate alone. Seedlings planted in autoclaved soil 3 days before inoculation with Pn198 or Pp99 did not have greater root weight than seedlings inoculated at the start of the experiment.

Propagules recovered from the soil at the end of each experiment had increased five- to sixfold from the initial density of 20 propagules $/ \mathrm{cm}^{3}$ of soil (Table 3 ). For both rootstocks, propagule density differed significantly among the treatments, but only increased in the treatments involving a co-inoculation of Pn117 with Pn198. Overall, the recovery of propagules from the soil among the treatments was consistent. The hypovirulent isolate $\mathrm{Pn} 117$ was recovered at the same levels as the two virulent isolates.

Competition between isolates of Phytophthora spp. Infection of the roots by hypovirulent Pn117 produced the same levels of colonies as the virulent isolate of P. palmivora, Pp99 (Figs. 2 and 3 ). For both the sweet orange and Swingle citrumelo rootstocks, co-inoculation of Pp99 and Pn117 increased recovery of Pp99 and decreased recovery of Pn117 compared with the single isolate inoculations. Preinoculation of Pn117 followed by Pp99 resulted in a sharp increase in the number of Pn117 isolates recovered, and a decrease in the number of Pp99 isolates recovered compared with the co-inoculation.

\section{DISCUSSION}

In the experiments conducted, precolonization of the host roots by the hypovirulent isolate Pn117 of P. nicotianae provided pro- tection from the virulent isolates of $P$. nicotianae and $P$. palmivora. Pn117 is considered hypovirulent because this isolate consistently caused less root rot disease than the virulent isolates, Pn198 and Pp99. A co-inoculation of the hypovirulent isolate with either virulent isolate resulted in the same amount of disease as a single inoculation with a virulent isolate. In control treatments where seedlings were planted in autoclaved soil 3 days before being inoculated with a virulent isolate, disease severity was not reduced. This indicates that $\mathrm{Pn} 117$ is responsible for the reduction in disease severity when this isolate is allowed to precolonize the roots. Other factors, such as induction of resistance genes from

TABLE 2. Dry weight of fibrous roots of two citrus rootstock seedling types inoculated with three isolates of Phytophthora spp. representing different virulence types: hypovirulent isolate Pn117 of Phytophthora nicotianae (abbreviation: 117) and virulent isolates Pn198 of P. nicotianae and Pp99 of P. palmivora (abbreviations: 198 and 99, respectively) ${ }^{\mathrm{u}}$

\begin{tabular}{|c|c|c|c|c|}
\hline \multirow[b]{3}{*}{ Treatment } & \multicolumn{4}{|c|}{ Root weight (g) } \\
\hline & \multicolumn{2}{|c|}{ Cleopatra mandarin } & \multicolumn{2}{|c|}{ Swingle citrumelo } \\
\hline & Exp. 1 & Exp. 2 & Exp. 1 & Exp. 2 \\
\hline 117 & $0.327 \mathrm{~b}$ & $0.334 \mathrm{~b}$ & $0.546 \mathrm{~b}$ & $0.477 \mathrm{~b}$ \\
\hline 198 & $0.214 \mathrm{c}$ & $0.204 \mathrm{~cd}$ & $0.282 \mathrm{c}$ & $0.307 \mathrm{c}$ \\
\hline 99 & $0.229 \mathrm{c}$ & $0.218 \mathrm{~cd}$ & $0.323 \mathrm{c}$ & $0.358 \mathrm{c}$ \\
\hline $117+198$ & $0.224 \mathrm{c}$ & $0.178 \mathrm{~cd}$ & $0.330 \mathrm{c}$ & $0.333 \mathrm{c}$ \\
\hline $117+99$ & $0.217 \mathrm{c}$ & $0.193 \mathrm{~cd}$ & $0.309 \mathrm{c}$ & $0.359 \mathrm{c}$ \\
\hline $3 \mathrm{~d} 117+198^{\mathrm{v}}$ & $0.357 \mathrm{~b}$ & $0.321 \mathrm{~b}$ & $0.535 \mathrm{~b}$ & $0.431 \mathrm{~b}$ \\
\hline $3 d+198^{w}$ & $0.191 \mathrm{c}$ & $0.246 \mathrm{c}$ & $0.316 \mathrm{c}$ & $0.320 \mathrm{c}$ \\
\hline 3 d 117+noninfest ${ }^{\mathrm{x}}$ & $0.342 \mathrm{~b}$ & $0.329 \mathrm{~b}$ & $0.512 \mathrm{~b}$ & $0.460 \mathrm{~b}$ \\
\hline 3 d 117+99y & $0.338 \mathrm{~b}$ & $0.306 \mathrm{~b}$ & $0.503 \mathrm{~b}$ & $0.446 \mathrm{~b}$ \\
\hline $3 d+99^{z}$ & $0.172 \mathrm{c}$ & $0.163 \mathrm{~d}$ & $0.260 \mathrm{c}$ & $0.344 \mathrm{c}$ \\
\hline Control & $0.417 \mathrm{a}$ & $0.392 \mathrm{a}$ & $0.661 \mathrm{a}$ & $0.598 \mathrm{a}$ \\
\hline
\end{tabular}

u The hypovirulent isolate was introduced as a preinoculation or co-inoculation with the virulent isolates. All seedlings were harvested 4 weeks after planting. Means within a column with a common letter are not significantly different according to the Tukey's studentized range test at $P \leq 0.05$.

${ }^{v}$ Roots were inoculated with Pn117 for 3 days prior to inoculation with Pn198.

${ }^{w}$ Roots were planted in noninfested soil for 3 days prior to inoculation with Pn198.

${ }^{x}$ Roots were inoculated with Pn117 for 3 days and then planted into noninfested soil.

y Roots were inoculated with Pn117 for 3 days prior to inoculation with Pp99.

${ }^{\mathrm{z}}$ Roots were planted into noninfested soil for 3 days prior to inoculation with Pp99.

TABLE 1. Median and relative treatment effects $\left(p_{\mathrm{ijk}}\right)$ for root disease severity of two citrus seedling types inoculated with three isolates of Phytophthora spp. representing different virulence types (hypovirulent Pn117 and virulent Pn198 and Pp99)

\begin{tabular}{|c|c|c|c|c|c|c|}
\hline \multirow[b]{3}{*}{ Treatment $^{\mathrm{u}}$} & \multicolumn{6}{|c|}{ Rootstocks } \\
\hline & \multicolumn{3}{|c|}{ Cleopatra mandarin } & \multicolumn{3}{|c|}{ Swingle citrumelo } \\
\hline & Median & $p_{\mathrm{ijk}}$ & $95 \%$ CI for $p_{\mathrm{ijk}}$ & Median & $p_{\mathrm{ijk}}$ & $95 \%$ CI for $p_{\mathrm{ijk}}$ \\
\hline 117 & 2 & 0.334 & $0.240,0.445$ & 2 & 0.334 & $0.240,0.445$ \\
\hline 198 & 3 & 0.678 & $0.562,0.774$ & 3 & 0.643 & $0.536,0.736$ \\
\hline 99 & 3 & 0.678 & $0.562,0.774$ & 3 & 0.643 & $0.536,0.736$ \\
\hline $117+198$ & 3 & 0.678 & $0.562,0.774$ & 3 & 0.643 & $0.536,0.736$ \\
\hline 3 d $117+198^{v}$ & 2 & 0.300 & $0.213,0.406$ & 2.5 & 0.368 & $0.270,0.480$ \\
\hline $3 d+198^{w}$ & 4 & 0.782 & $0.663,0.864$ & 3 & 0.643 & $0.536,0.736$ \\
\hline 3 d 117+noninfest ${ }^{\mathrm{x}}$ & 2 & 0.300 & $0.213,0.406$ & 2 & 0.334 & $0.240,0.445$ \\
\hline $117+99$ & 3.5 & 0.712 & $0.591,0.807$ & 3 & 0.643 & $0.536,0.736$ \\
\hline 3 d 117+99y & 2.5 & 0.368 & $0.270,0.480$ & 2.5 & 0.368 & $0.270,0.480$ \\
\hline $3 d+99^{z}$ & 4 & 0.747 & $0.625,0.837$ & 3.5 & 0.712 & $0.591,0.807$ \\
\hline Control & 1 & 0.045 & $0.045,0.045$ & 1 & 0.045 & $0.045,0.045$ \\
\hline
\end{tabular}

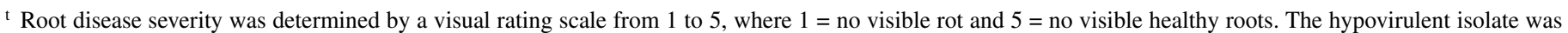
introduced as a preinoculation and co-inoculation with the virulent isolates. All seedlings were harvested 4 weeks after planting.

u Abbreviations: $117=$ isolate Pn117 of Phytophthora nicotianae, $198=$ isolate Pn198 of P. nicotianae, and $99=$ isolate Pp99 of $P$. palmivora.

${ }^{v}$ Roots were inoculated with isolate Pn117 3 days prior to inoculation with isolate Pn198.

${ }^{w}$ Seedling were planted into noninfested soil for 3 days prior to inoculation with isolate Pn 198.

${ }^{x}$ Roots were inoculated with isolate Pn117 for 3 days and were transplanted into noninfested soil.

y Roots were inoculated with isolate Pn117 3 days prior to inoculation with isolate Pp99.

z Seedling were planted into noninfested soil for 3 days and were transplanted into soil containing Pp99. 
wounding during the replanting process or incidental introduction of biological control organisms, can be ruled out as causes for the reduction of disease.

Research with avocado root rot suggests that the weak pathogen of one Phytophthora sp. can be used as a biological control against a virulent isolate of a different Phytophthora sp. P. nicotianae was active as a biological control agent against $P$. cinnamomi on avocado (1). Protection was observed if the host was preinoculated with $P$. nicotianae at least $2 \mathrm{~h}$ before being inoculated with the pathogen $P$. cinnamomi. Increasing the preinoculation time to $48 \mathrm{~h}$ resulted in a greater reduction in disease than the 2-h preinoculation time. No disease reduction was observed with a co-inoculation of the two Phytophthora spp.

Space and resource competition between the hypovirulent and virulent isolates may play a role in the biological control interac- tion. In the competition study, the hypovirulent isolate Pn117 infected and reproduced on roots to the same extent as the virulent isolates. An increase in recovery of $\mathrm{Pp} 99$ isolate of $P$. palmivora occurred with the co-inoculation of the roots with Pn117 and Pp99. This result was consistent with a competition study between isolates of $P$. nicotianae and $P$. palmivora (25). P. palmivora is more aggressive and produces sporangia more rapidly and in greater numbers on infected tissue than does $P$. nicotianae $(11,25)$. Over a range of inoculum densities of a mixed inoculation, populations of $P$. palmivora were consistently higher than those of $P$. nicotianae. After infection, the cortical cells of citrus and other plants leak electrolytes and compounds such as ketone sugars and amino acids $(14,24)$. Ketone sugars, such as sucrose, are a preferred carbohydrate source for Phytophthora spp. growth in culture and population development in the citrus rhizosphere

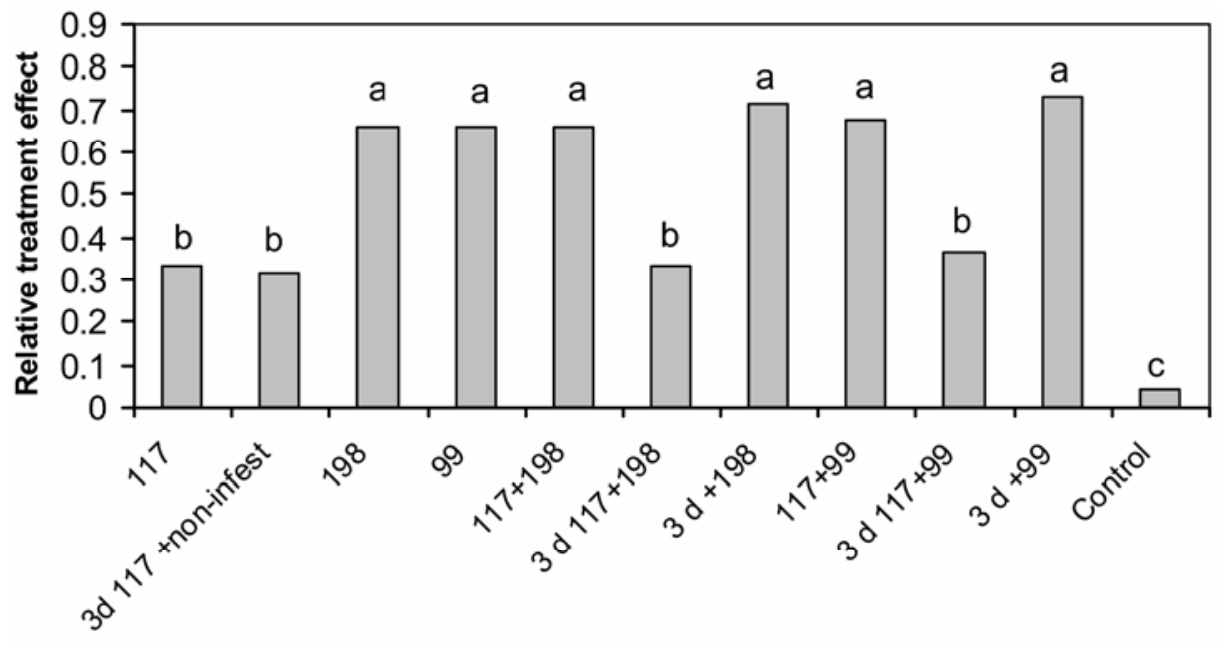

Treatments

Fig. 1. Root disease severity after pooling the results from the two citrus rootstock seedling types (Cleopatra mandarin and Swingle citrumelo) inoculated with three isolates of Phytophthora spp. representing different virulence types: hypovirulent isolate Pn117 of Phytophthora nicotianae, and virulent isolates Pn198 of P. nicotianae and Pp99 of P. palmivora. The hypovirulent isolate was introduced as a preinoculation and co-inoculation with the virulent isolates. Treatments were (i) $117=$ Pn117, (ii) $198=$ Pn198, (iii) $99=$ Pp99, (iv) $117+198=$ co-inoculation with Pn117 and Pn198, (v) $117+99=$ co-inoculation with Pn117 and Pp99, (vi) 3 d $117+198=$ roots inoculated with Pn117 for 3 days prior to inoculation with Pn198, (vii) 3 d $117+99=$ roots inoculated with Pn117 for 3 days prior to inoculation with Pp99, (viii) 3d $117+$ noninfest $=$ roots inoculated with isolate Pn117 for 3 days and then planted into noninfested soil, (ix) $3 \mathrm{~d}+198=$ roots planted into noninfested soil for 3 days prior to inoculation with Pn198, and (x) $3 d+99=$ roots planted into noninfested soil for 3 days prior to inoculation with Pp99. Treatment bars with a common letter are not significantly different according to the Tukey's studentized range test at $P \leq 0.05$.

TABLE 3. Propagules in the soil recovered from two citrus rootstock seedling types inoculated with three isolates of Phytophthora spp. representing different virulence types: hypovirulent isolate Pn117 of Phytophthora nicotianae (abbreviation: 117) and virulent isolates Pn198 of P. nicotianae and Pp99 of P. palmivora (abbreviations: 198 and 99 , respectively) ${ }^{\mathrm{u}}$

\begin{tabular}{|c|c|c|c|c|}
\hline \multirow[b]{3}{*}{ Treatment } & \multicolumn{4}{|c|}{ Propagules $/ \mathrm{cm}^{3}$ of soil } \\
\hline & \multicolumn{2}{|c|}{ Cleopatra mandarin } & \multicolumn{2}{|c|}{ Swingle citrumelo } \\
\hline & Pn117, Pn198, or both & Pp99 & Pn117, Pn198, or both & Pp99 \\
\hline 198 & $114 \mathrm{a}$ & 0 & $112 \mathrm{a}$ & 0 \\
\hline 99 & 0 & $122 \mathrm{a}$ & 0 & $92 \mathrm{a}$ \\
\hline $117+198$ & $166 \mathrm{~b}$ & 0 & $194 \mathrm{~b}$ & 0 \\
\hline $117+99$ & $106 \mathrm{a}$ & $102 \mathrm{a}$ & $108 \mathrm{a}$ & $98 \mathrm{a}$ \\
\hline $3 \mathrm{~d} 117+$ noninfest $^{\mathrm{x}}$ & $108 \mathrm{a}$ & 0 & $106 \mathrm{a}$ & 0 \\
\hline $3 \mathrm{~d} 117+99^{y}$ & $104 \mathrm{a}$ & $102 \mathrm{a}$ & $102 \mathrm{a}$ & $90 \mathrm{a}$ \\
\hline $3 d+99^{z}$ & 0 & $100 \mathrm{a}$ & 0 & $104 \mathrm{a}$ \\
\hline Control & 0 & 0 & 0 & 0 \\
\hline
\end{tabular}

u The hypovirulent isolate was introduced as a preinoculation and co-inoculation with the virulent isolates. All seedlings were harvested 4 weeks after planting.

Means within a column with a common letter are not significantly different according to the Tukey's studentized range test at $P \leq 0.05$.

v Roots were inoculated with Pn117 3 days prior to inoculation with Pn198.

${ }^{w}$ Seedling were planted into noninfested soil for 3 days prior to inoculation with Pn198.

${ }^{x}$ Roots were inoculated with Pn117 for 3 days and were transplanted into noninfested soil.

y Roots were inoculated with Pn117 3 days prior to inoculation with Pp99.

${ }^{\mathrm{z}}$ Roots were planted into noninfested soil for 3 days prior to inoculation with Pp99. 
$(2,12)$. Amino acids are involved in chemotaxis of zoospores to infection sites $(12,14)$. P palmivora can colonize aggressively when the root cortex is coincidently infected by $P$. nicotianae (25). Conversely, Pp99 recovery is reduced if Pn117 is preinoculated compared with the single inoculation with $P$. palmivora. In this case, preestablishment of the hypovirulent isolate in the root cortex may consume nonstructural carbohydrates, reducing subsequent colonization by $P$. palmivora.

Analogous to the interaction between hypovirulent and virulent Phytophthora spp., prior infection by the citrus nematode, Tylenchulus semipenetrans, reduces $P$. nicotianae infection and root damage (3). Several hypotheses have been explored to explain the interaction, including the development of an antagonistic microflora associated with the females and their egg masses protruding into the rhizosphere (4). In orchards, both parasites key off of seasonal availability of nonstructural carbohydrates, with citrus nematode population dynamics more related to starch and $P$. nicotianae to ketone sugars in fibrous roots (2). Therefore, like the

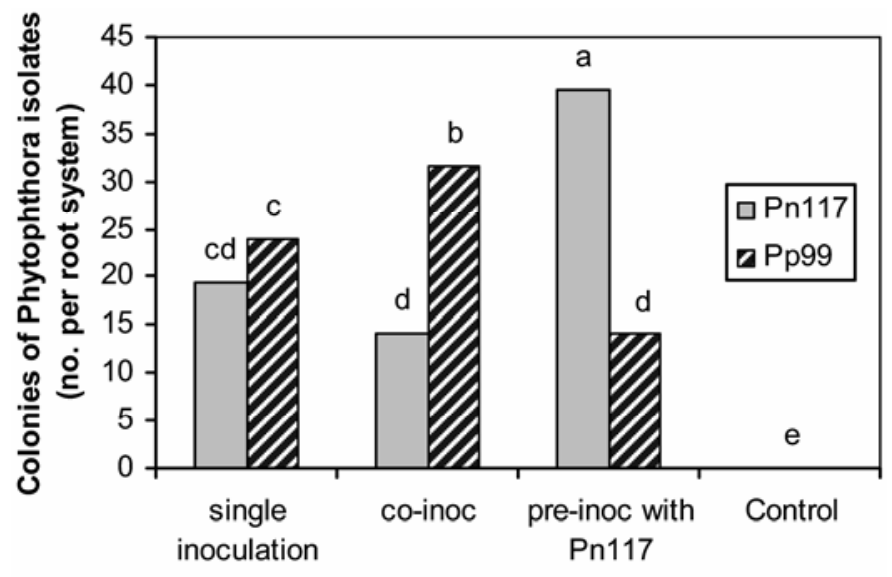

Treatments

Fig. 2. Average number of colonies of Phytophthora spp. recovered from the roots of sweet orange seedlings. Treatments were (i) inoculation with isolate Pp99 of Phytophthora palmivora, (ii) the hypovirulent isolate Pn117 of P. nicotianae, (iii) a co-inoculation of Pp99 and Pn117, or (iv) a preinoculation of Pn117 followed by Pp99. The incubation period was 3 days. Treatment bars with a common letter are not significantly different according to the Tukey's studentized range test at $P \leq 0.05$.

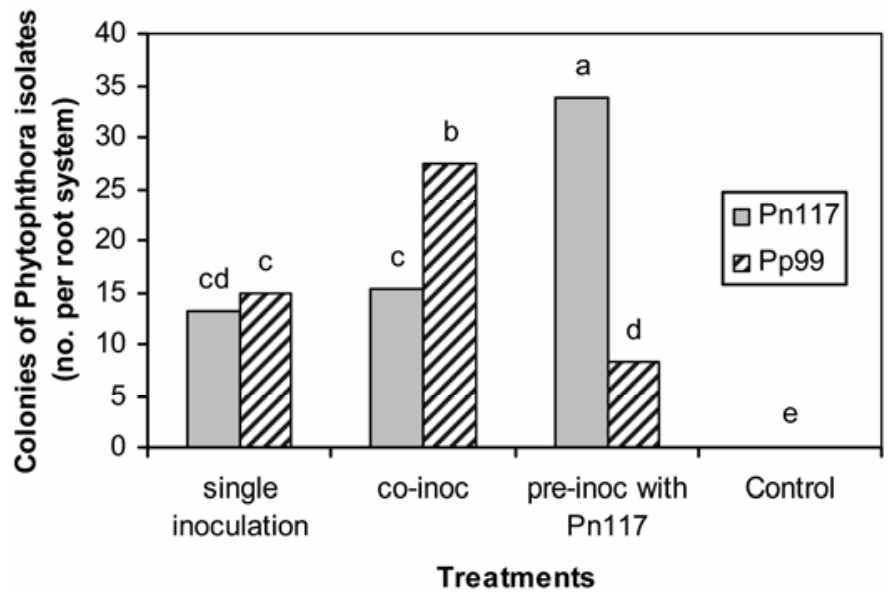

Fig. 3. Average number of colonies of Phytophthora spp. recovered from the roots of Swingle citrumelo seedlings. Treatments were (i) inoculation with isolate Pp99 of Phytophthora palmivora, (ii) the hypovirulent isolate Pn117 of P. nicotianae, (iii) a co-inoculation of $\mathrm{Pp} 99$ and $\mathrm{Pn} 117$, or (iv) a preinoculation of the Pn117 isolate followed by Pp99. The incubation period was 3 days. Treatment bars with a common letter are not significantly different according to the Tukey's studentized range test at $P \leq 0.05$. hypovirulent isolate of $P$. nicotianae, the semi-endoparasitic nematode may compete directly for nonstructural carbohydrates in the cortex with $P$. nicotianae.

Previous work with isolate Pn117 isolate demonstrated potential to be deployed as a biological control agent. Sunburst tangerine on Cleopatra mandarin rootstock trees inoculated with Pn117 of $P$. nicotianae prior to planting in a Phytophthora spp.infested orchard were expected to be the most diseased but, instead, were the healthiest (J. H. Graham, unpublished data). The experiment was not evaluated until 7 months after planting; therefore, the treatment had a long-lasting effect in the field site. In the first experiment of the present study, Pn117 was recovered from the soil in the greenhouse 4 weeks after inoculation. The propagule density increased from five- to sixfold from the initial concentration. In the competition study, the hypovirulent Pn117 infected the roots at the same level as the virulent isolates, Pp99 and Pn198. These results suggest that, although the Pn117 causes less disease, it is not impaired in ability to infect and colonize roots and to produce long-lasting propagules in the soil.

The sustained biological control effects of the hypovirulent isolate are in contrast to the control by Pseudomonas putida, which was maintained only by weekly augmentations of citrus rhizosphere soils under field conditions (20). Other biocontrol agents require soil amendments to maintain populations and biological control activity. Trichoderma viride proliferated only when the hyphae were in contact with bran (15). Penicillium funiculosum required a wheat bran-peat moss substrate to maintain suppressive control (5), whereas Pythium nunn required an amendment of ground oat in the soil to reduce sweet orange root rot (6). Phytophthora nicotianae Pn117 may be a promising biological control organism in citrus because the hypovirulent isolate effectively colonizes the host roots and persists without soil amendments or repeated applications.

The risk of using a hypovirulent Phytophthora isolate as a biological control agent has not been evaluated. For this reason, citrus growers may not accept trees that have been inoculated with an attenuated pathogen if there is a risk of the pathogen regaining virulence. $P$. nicotianae produces large numbers of sporangia and zoospores under favorable conditions (25). Over time, more virulent propagules in the population would be predicted to out-compete less virulent ones. Additional greenhouse and field trials would be needed to determine the efficacy and stability of the Pn117 isolate as a biological control.

\section{ACKNOWLEDGMENTS}

We thank R. J. Stewart for assistance in statistical analysis and H. M. Rubio and D. B. Bright for technical assistance.

\section{LITERATURE CITED}

1. Dolan, T. E., Cohen, Y., and Coffey, M. D. 1986. Protection of Persea species against Phytophthora cinnamomi and $P$. citricola by prior inoculation with a citrus isolate of $P$. parasitica. Phytopathology 76:194198.

2. Duncan, L. W., Graham, J. H., and Timmer, L. W. 1993. Seasonal patterns associated with Tylenchulus semipenetrans and Phytophthora parasitica in the citrus rhizosphere. Phytopathology 83:573-581.

3. El-Borai, F. E., Duncan, L. W., and Graham, J. H. 2002. Infection of citrus roots by Tylenchulus semipenetrans reduces root infection by Phytophthora nicotianae. J. Nematol. 34:384-389.

4. El-Borai, F. E., Duncan, L. W., and Graham, J. H. 2003. Tylenchulus semipenetrans alters the microbial community in the citrus rhizosphere. J. Nematol. 35:167-177.

5. Fang, J. G., and Tsao, P. H. 1995. Efficacy of Penicillium funiculosum as a biological control agent against Phytophthora root rots of azalea and citrus. Phytopathology 85:871-878.

6. Fang, J. G., and Tsao, P. H. 1995. Evaluation of Pythium nunn as a potential biocontrol agent against Phytophthora root rots of azalea and citrus. Phytopathology 85:29-36.

7. Graham, J. H. 1995. Root regeneration and tolerance of citrus rootstocks 
to root rot caused by Phytophthora nicotianae. Phytopathology 85:111117.

8. Graham, J. H. 2004. Biological control of soilborne plant pathogens and nematodes. Pages 562-586 in: Principals and Applications of Soil Microbiology, 2nd ed. D. M. Sylvia, J. J. Fuhrmann, P. G. Hartel, and D. A. Zuberer, eds. Pearson Prentice Hall, Upper Saddle River, NJ.

9. Graham, J. H., and Kosola, K. R. 2000. Costs and benefits of citrus roots in relation to activity of root pathogens. Proc. Int. Citricult. IX Congr. Vol. II:921-925.

10. Graham, J. H., and Menge, J. A. 1999. Root health: Fungal diseases. Pages 126-135 in: Citrus Health Management. L. W. Timmer and L. W. Duncan, eds. American Phytopathological Society, St. Paul, MN.

11. Graham, J. H., Timmer, L. W., Drouillard, D. L., and Peever, T. L. 1998. Characterization of Phytophthora spp. causing outbreaks of citrus brown rot in Florida. Phytopathology 88:724-729.

12. Hohl, H. R. 1983. Nutrition of Phytophthora. Pages 41-54 in: Phytophthora, Its Biology, Taxonomy, Ecology, and Pathogenicity. D. C. Erwin, S. Bartnicki-Garcia, and P. H. Tsao, eds. American Phytopathological Society, St. Paul, MN.

13. Kookna, R. S., Di, H. J., and Aylmore, L. A. G. 1995. A field study of leaching and degradation of nine pesticides in a sandy soil. Aust. J. Soil. Res. 33:1019-1130.

14. Kuan, T. L., and Erwin, D. C. 1980. Predisposition effect of water saturation of soil on Phytophthora root rot of alfalfa. Phytopathology 70:981-986.

15. Lewis, J. A., and Papavizas, G. C. 1984. A new approach to stimulate population proliferation of Trichoderma species and other potential biocontrol fungi introduced into natural soils. Phytopathology 74:12401244.

16. Mitchell, D. J., Kannwischer-Mitchell, M. E., and Zentmyer, G. A. 1986. Isolating, identifying, and producing inoculum of Phytophthora spp.
Pages 63-66 in: Methods for Evaluating Pesticides for Control of Plant Pathogens. K. D. Hickey, ed. American Phytopathological Society, St. Paul, MN.

17. Nemec, S., Datnoff, L. E., and Strandberg, J. 1996. Efficacy of biocontrol agents in planting mixes to colonize plant roots and control root diseases of vegetables and citrus. Crop Prot. 15:735-742.

18. Sandler, H. A., Timmer, L. W., Graham, J. H., and Zitko, S. E. 1989. Effect of fungicide applications on populations of Phytophthora parasitica, and on feeder root densities and fruit yields of citrus trees. Plant Dis. 73:902-906.

19. Shah, D. A., and Madden, L. V. 2004. Nonparametric analysis of ordinal data in designed factorial experiments. Phytopathology 94:33-43.

20. Steddom, K., Becker, O., and Menge, J. A. 2002. Repetitive applications of the biocontrol agent Pseudomonas putida 06909-rif/nal and effects on populations of Phytophthora parasitica in citrus orchards. Phytopathology 92:850-856.

21. Timmer, L. W., Graham, J. H., and Zitko, S. E. 1998. Metalaxyl-resistant isolates of Phytophthora nicotianae: Occurrence, sensitivity, and competitive parasitic ability on citrus. Plant Dis. 82:254-261.

22. Timmer, L. W., Sandler, H. A., Graham, J. H., and Zitko, S. E. 1988. Sampling citrus orchards in Florida to estimate populations of Phytophthora parasitica. Phytopathology 78:940-944.

23. Tsao, P. H. 1971. Chlamydospore formation in sporangium-free liquid cultures of Phytophthora parasitica. Phytopathology 61:1412-1413.

24. Widmer, T. L., Graham, J. H., and Mitchell, D. J. 1998. Histological comparison of fibrous root infection of disease-tolerant and susceptible citrus hosts by Phytophthora nicotianae and P. palmivora. Phytopathology 88:389-395.

25. Zitko, S. E., and Timmer, L. W. 1994. Competitive parasitic abilities of Phytophthora parasitica and $P$. palmivora on fibrous roots of citrus. Phytopathology 84:1000-1004. 